Delft University of Technology

\title{
Skin-Stiffener Separation in T-Stiffened Composite Specimens in Postbuckling Condition
}

Zou, Duo; Bisagni, Chiara

DOI

10.1061/(ASCE)AS.1943-5525.0000849

Publication date

2018

Document Version

Accepted author manuscript

Published in

Journal of Aerospace Engineering

\section{Citation (APA)}

Zou, D., \& Bisagni, C. (2018). Skin-Stiffener Separation in T-Stiffened Composite Specimens in Postbuckling Condition. Journal of Aerospace Engineering, 31(4), [04018027].

https://doi.org/10.1061/(ASCE)AS.1943-5525.0000849

\section{Important note}

To cite this publication, please use the final published version (if applicable).

Please check the document version above.

\section{Copyright}

Other than for strictly personal use, it is not permitted to download, forward or distribute the text or part of it, without the consent of the author(s) and/or copyright holder(s), unless the work is under an open content license such as Creative Commons.

\section{Takedown policy}

Please contact us and provide details if you believe this document breaches copyrights.

We will remove access to the work immediately and investigate your claim. 


\title{
Study of skin-stiffener separation in T-stiffened composite specimens in post-buckling condition
}

\author{
Duo Zou ${ }^{1}$; Chiara Bisagni ${ }^{2}$ \\ ${ }^{1}$ Research Fellow, Faculty of Aerospace Engineering, Delft University of Technology, 2629HS Delft, \\ Netherlands. E-mail: D.Zou@tudelft.nl (D. Zou) \\ ${ }^{2}$ Professor, Faculty of Aerospace Engineering, Delft University of Technology, 2629HS Delft, Netherlands. \\ E-mail: C.Bisagni @ tudelft.nl (C. Bisagni)
}

Abstract: An experimental and numerical investigation was conducted to study the skin-stiffener separation of single T-shape stiffener specimens in post-buckling condition. Three specimens were manufactured with a centrally located Teflon insert, and were loaded in compression until collapse. Deformation patterns and separation evolution were monitored during the tests. To measure the fullfield displacements and the strain distributions of the specimens, Digital Image Correlation (DIC) system was used. Skin-stiffener separation was observed and measured with an ultrasound system. Finite Element (FE) analyses were conducted to capture interlaminar damage mechanism based on Virtual Crack Closure Technique. The numerical analysis well predicted the post-buckling deformation and the skin-stiffener separation behaviour. The close correlation between the experimental and numerical results allows for further exploitation of strength reserve in post-buckling region and wider design options for the next generation of composite aircraft designs.

Author keywords: Composite stiffened structures; Skin-stiffener separation; Compression; Postbuckling; Tests.

\section{Introduction}

Composite materials progressively substitute traditional materials in many fields due to their superior mechanical properties, significant weight saving and the ease with which they can be tailored (Armanios 1991). Nowadays they are used in civil engineering applications and their use is also revolutionizing the way aircraft and spacecraft structures are designed. A recent challenge in economic 
fabrication in aerospace engineering has moved the composites application to new levels of automated manufacturing process.

A wide range of literature covers experimental results of post-buckling behaviour of composite stiffened structures. These studies evaluate the factors which can affect the characteristics of postbuckling and collapse behaviour of stiffened structures, such as loading conditions (Bisagni and Cordisco 2003; Abramovich et al. 2008; Krueger et al. 2005), the stiffener configuration (Zimmermann et al. 2006), the thickness ratio between skin and stiffener (Falzon et al. 2008), and the stiffener pitch (Ambur et al. 2004; Bisagni 2000; Orifici et al. 2009; Lauterbach et al. 2010). These composite stiffened structures ranged from stiffened flat panels (Orifici et al. 2008), to curved panels and cylinders (Bisagni and Cordisco 2003). In the studies of Bisagni and Cordisco (Bisagni and Cordisco 2003; Bisagni and Cordisco 2006), experimental activities were performed on Carbon Fiber Reinforced Plastics (CFRP) shells under axial and torsion loading, applied in combination and separately. Their test results show that the shells are capable to sustain load in post-buckling field without any visible failure mechanisms. Abramovich et al. (Abramovich et al. 2008) and Featherston et al. (Featherston and Watson 2006) investigated the buckling and post-buckling behaviour of composite panels, subject to a varying combination of shear and axial loading/in-plane bending. The work of Krueger et al. (Krueger et al. 2005) regards the shear-loaded panel and the resulting out-ofplane deformations initiated skin-stiffener separation at the location of an embedded defect. Abramovich and his co-authors (Abramovich et al. 2008) have also shown that the torsion boxes made of two stringer-stiffened cylindrical panels have a very high post-buckling carrying capacity, which is dependent on stiffener geometry and layup.

Many of these experiments have been conducted on stiffened panels with multiple stiffeners to investigate post-buckling behaviour and collapse phenomena under compression or shear load, and to further validate the corresponding analytical or numerical models. Few tests were performed on single-stiffened composite specimens considering the skin-stiffener separation in the post-buckling range (Bisagni 2006; Orifici et al. 2008; Bisagni et al. 2011; Bisagni and Davila 2014; Davila and Bisagni 2017). Manufacturing and testing of full-scale composite components to evaluate skinstiffener separation performance is quite complex and expensive. There has been considerable effort to 
reduce the complexity of these tests by developing small-scale tests on laboratory size element type specimens and bridging the gap between coupon tests and full-scale composite components. The tests on element type specimens can characterize the skin-stiffener separation by mimicking the same conditions as the multi-stiffened panels. These specimens on the element level are usually made of a single stiffener and can be tested in fairly large numbers due to the relatively low manufacturing costs.

The concern on whether a single stiffener configuration can be used to study the response and collapse of a multiple stiffener panel has been evaluated by a few researchers (Orifici et al. 2009; Bisagni et al. 2011; Vescovini et al. 2013; Bisagni and Davila 2014). In the studies (Orifici et al. 2008; Orifici et al. 2009), the initiation of interlaminar damage in the skin-stiffener interface had been predicted by using a global-local technique. It was also shown that a progressive failure analysis performed with the Virtual Crack Closure Technique (VCCT) can be used to predict critical damage mechanisms. In particular, global-local analysis regards a set of numerical techniques which aim to reduce the total computational time while maintaining a given level of solution accuracy. In this technique, the development of a global model of the full-scale structure was essential to determine the complete deformation fields, which were then implemented as boundary conditions on a local threedimensional model. In the local model, a strength criterion was introduced and monitored at all elements to predict the delamination onset between the skin and stiffener. In the work of one of the authors (Vescovini et al. 2013), a global-local damage analysis method was also proposed, and it indicated that a detailed local model can be used to scan the global model and identify the locations that are most critical for damage tolerance.

In the earlier work of one of the authors (Bisagni 2006), it was proposed to study the skin-stiffener separation on a simple specimen configuration with one L-shape stiffener bonded to the skin. The specimen was studied experimentally and the test results were used to validate the finite element analysis results conducted using ABAQUS and VCCT. Later, four compression test campaigns were carried out on single stiffener specimens composed of co-cured skin and hat stiffener (Bisagni et al. 2011; Bisagni and Davila 2014; Dávila and Bisagni 2017). These tests represents a level of complexity that can bridge the gap between the coupon tests used for material characterization and the structural 
component tests required for panel response. Moreover, the advantages of single stiffener specimen are its relatively low manufacturing and testing costs, and less computational efforts.

The work presented here describes the experimental and numerical investigations performed on single stiffener compression specimens with a co-cured T-stiffener in post-buckling conditions. The specimen was designed with a Teflon film insert in the skin-stiffener interface to evaluate the structural integrity of stiffened structures. The Teflon insert is used to simulate defects during manufacturing process.

In the testing, the specimens were loaded in compression until the collapse. The tests focused on the initiation and evolution of skin-stiffener separation in the initial debonded area subjected to postbuckling deformations. A three-dimensional DIC system was used to monitor the deformation responses and ultrasonic scans were performed to evaluate the damage evolution. In the numerical analysis, a model for capturing interlaminar crack growth using the VCCT was developed. The experimental and numerical results are compared in terms of post-buckling response, damage initiation and damage evolution.

The results of the current study can provide further understanding of the response of the composite structures with pre-existing damages in post-buckling conditions, and estimate the residual strength by giving increased database necessary to develop damage tolerance criteria for structural design.

\section{Tests}

\section{Test Specimens}

The specimens were designed with a co-cured T-shape stiffener. The interest was to study how the delamination initiates and propagates with an embedded Teflon insert under compression loading condition.

The test specimens investigated in the present study have a length of $300 \mathrm{~mm}$ and a width of 150 $\mathrm{mm}$. The T-section stiffener includes a stiffener flange with width of $60 \mathrm{~mm}$ and a stiffener web with height of $30 \mathrm{~mm}$. Teflon insert was introduced between skin and stiffener across the whole flange 
width in order to simulate manufacturing defects. The insert was $30 \mathrm{~mm}$ long and centrally located with regards to the specimen length, as shown in Fig. 1.

The laminates are made of IM7/8552 carbon-epoxy prepregs produced by Hexcel. Each ply has a nominal thickness of $0.125 \mathrm{~mm}$. The skin and the stiffener flange have eight layers with a quasiisotropic stacking sequence $[0 / 45 /-45 / 90]_{s}$, while the stiffener web has sixteen layers with a quasiisotropic stacking sequence [0/45/-45/90/90/-45/45/0] . The stack sequences are shown in Fig. 2.

The mechanical properties of the unidirectional prepreg material IM7-8552 are reported in Table 1 and the interlaminar properties are reported in Table 2 (Camanho et al. 2007). These properties include fracture toughnesses in mode I and II, and the B-K mode-mixity parameter.

All the tested specimens were casted with aluminium potting to their end pieces. The tabs allowed a uniform distribution of the load during the tests. Casting height of the tabs was $30 \mathrm{~mm}$ long at each side, so the actual length was limited to the central part and equal to $240 \mathrm{~mm}$. The three specimens are denoted as SP1, SP2 and SP3, respectively.

\section{Testing Set-up and Procedure}

The experiments were performed with a hydraulic MTS test rig. In order to observe the structural behaviour using DIC system, the specimens were speckled on the skin external surface where there is no stiffener.

The specimens were quasi-statically loaded in displacement-control at a constant velocity equal to $0.2 \mathrm{~mm} / \mathrm{min}$. During the tests, the displacement and strain fields were measured and monitored by three-dimensional DIC VIC-3D system (VIC-3D. 2010). Two digital video cameras (Q400 system with $15 \mathrm{~mm}$ lens) were used and light source was required to enhance observation. The data from the DIC were captured at a frequency of $1 \mathrm{~Hz}$.

During the loading, it was decided to stop the tests at different load levels. When the damage was suspected, careful observations were made and the compression was released to zero and the specimen was removed for an ultrasonic C-scan. Then, a new axial displacement was applied to the specimen until the next possible skin-stiffener separation was detected and the specimen was removed once again to check if there was any damage initiation or damage propagation. The same steps were 
repeated until the delamination evolution progress was captured. The load has been increased until the collapse.

During these steps, axial displacement, load, strains and out-of-plane displacements were recorded. The strain maps on deformed surfaces from DIC system were tracked to monitor the correspondence of the damage locations. The maximal strains provided local information on damage.

The ultrasonic C-scan is a non-destructive technique equipment to examine defects and allows to determine the damaged zones with a two-dimensional representation. The specimen and the transducer are sprayed with water which acts as the coupling medium. The signal is transmitted to the specimen by a transducer to which the initial signal is partially reflected back at defect sites. The frequency of the current C-scan ranges from $0.5 \mathrm{MHz}$ to $20 \mathrm{MHz}$ and its maximal scanning speed is $400 \mathrm{~mm} / \mathrm{s}$. It is noted that the ultrasound probe was scanning on the external surface of the skin where there was no stiffener. As a consequence, the C-scan image obtained had to be rotated $180^{\circ}$ clockwise to match with the back view of the skin internal surface where there was the stiffener, so to observe the skin-stiffener separation.

\section{Experimental Results}

Specimen SP1 was the first specimen to be tested. The initial buckling mode showed antisymmetric half-waves with respect to the stiffener along the longitudinal direction. As the load increased, the deflection of the skin became more visible. Fig. 3a presents the deflection of the skin at $27.9 \mathrm{kN}$ in the post-buckling field. Fig. 3b illustrates the contoured displacement fields from DIC system at the same load. The out-of-plane deformation at one side of the skin was equal to $10.2 \mathrm{~mm}$ and equal to $8.7 \mathrm{~mm}$ on the other side of the skin with a difference of $14.7 \%$. The stiffener web bended towards the direction where the out-of-plane displacements were most negative.

The C-scan was performed immediately after $27.9 \mathrm{kN}$ and no opening was observed in the predamaged area. At approximately $35.1 \mathrm{kN}$, the out-of-plane displacement increased to maximal value of $11.8 \mathrm{~mm}$ as presented in Fig. 4a. The strain in the stiffener flange close to Teflon insert area reached $5150 \mu \varepsilon$ (as shown in Fig. 4b), where the skin-stiffener separation initiated. It is therefore indicated 
that the maximal strain was matched with the damage initiation location. The axial compression was then released to zero and C-scan was carried out, as shown in Fig. 4c.

After C-scan, specimen SP1 was reloaded. The collapse occurred suddenly at approximately 34.9 kN. Two major failure mechanisms were observed: skin-stiffener separation and stiffener fracture. There was a transverse fracture on the web and flange of the stiffener. Free edge delamination was also observed in the stiffener web.

In order to compare the similarity and difference of structural responses for three specimens, it has been decided to stop the tests and perform ultrasonic scans on the remaining specimens SP2 and SP3 at the same load levels, $27.9 \mathrm{kN}$ and $35.1 \mathrm{kN}$.

Specimen SP2 was tested with two additional LVDTs to check the parallelism of the loading platform and to ensure that the two ends of the specimen remain parallel during the test. The data from LVDTs did provide identical results to the measurements from the test rig.

The initial buckling mode of the skin was characterized by a half-sine wave. The out-of-plane deflection of the skin expanded as the applied load increased. Fig. 5a shows the post-buckling deformation at approximately 27.9 kN. A DIC image is illustrated in Fig. 5b. Similar to specimen SP1, the stiffener web bended towards the direction of the skin side with larger out-of-plane deformation. However, a small difference of $5.6 \%$ between specimens SP1 and SP2 was found in the most negative deformation magnitudes (10.2 $\mathrm{mm}$ for specimen SP1 and $9.6 \mathrm{~mm}$ for specimen SP2), and it was probably due to the initial imperfections.

After the stiffener web deformed into a larger extent, the skin-stiffener separation initiated at load level of $35.12 \mathrm{kN}$. The delamination surface lied near the center of stiffener flange where the smaller out-of-plane displacement was obtained (Fig. 6a and Fig. 6b). The skin and the stiffener separated over a larger area at approximately $37.58 \mathrm{kN}$ (Fig. 6c and Fig. 6d) on the same side of the skin where the out-of-plane displacement reached $11.6 \mathrm{~mm}$.

After the ultrasonic scan, specimen SP2 was reloaded until final collapse that happened at a load level of approximately $36.96 \mathrm{kN}$. The failure mode of specimen SP2 was similar to specimen SP1 in terms of dominant skin-stiffener separation. 
Specimen SP3 was the last specimen tested. The buckling and post-buckling deformation patterns

of specimen SP3 were similar to the previous two tested specimens. The delamination onset of specimen SP3 was monitored at the load level of $35.09 \mathrm{kN}$ and skin-stiffener separation initiated at the interface opposite to bending direction of stiffener web. Further delamination propagation was measured at the load levels of $37.21 \mathrm{kN}$ and $37.08 \mathrm{kN}$, as shown in Fig. 7.

Fig. 7a and Fig. 7c represent the DIC out-of-plane deformations. The C-scans (Fig. 7b and Fig. 7d) indicated that the delamination propagated in a stable way before the final failure. The delamination surface propagated at an angle of approximately $45^{\circ}$.

The specimen SP3 collapsed at a load level of approximately $36.26 \mathrm{kN}$. The dominant failure modes were identical to those ones of specimen SP1 except for the fact that it was observed fiber damage on the skin surface.

\section{Comparison of Test Results}

The load versus shortening curves measured on the three specimens during the compression tests are reported in Fig. 8a. They exhibited the same stiffness in the pre-buckling phase and diverged slightly above the load level of $10 \mathrm{kN}$. Due to the gradual increase of the out-of-plane displacement, it was difficult to identify a unique point of buckling.

During the test, the available ultrasonic C-scan can only be carried out by removing the specimen from test machine. Therefore several loading-unloading-reloading procedures had been employed. To understand the change in stiffness stemming from repeated loading, load versus end shortening curves of the loading portions from four loading runs on specimen SP2 are illustrated in Fig. 8b. After run 1, C-scan result indicated that there was no delamination between the skin and the stiffener. It is observed that the load-shortening curve from run 2 overlapped with run 1 upon $25 \mathrm{kN}$. After the second testing run, delamination initiation was found at the central area of the stiffener flange. Despite the delamination initiated above $35.12 \mathrm{kN}$, the specimen SP2 did not show a reduction of stiffness even in post-buckling filed. This phenomena indicated that the composite stiffened structure has strong post-buckling strength reserve capability. After the subsequent reloading, the delamination propagated in the interface and the load-shortening curve overlapped with run 2. The final testing run 
demonstrated a reduced post-buckling stiffness because of a significant delaminated surface from run 3. As can be seen in Fig. 8b, at the same load level of $35 \mathrm{kN}$, the post-buckling deformations of run 3 were similar to that of run 4. It further claims that the influence of the repeated loading is of small significance when it takes into account the delamination propagation process.

For all three specimens, the delamination initiated on the opposite side where the stiffener web bended towards. The delamination onset of specimen SP3 was visible as a load drop at the load slightly higher than $35 \mathrm{kN}$. During the delamination propagation process, the stiffness of the structure was reduced accordingly. The delamination propagation of specimen SP3 at load $37.21 \mathrm{kN}$ reached maximal strain $5273 \mu \varepsilon$ (Fig. 9), which was only $2.3 \%$ higher than delamination initiation strain of $5150 \mu \varepsilon$ of specimen SP1 at $35.1 \mathrm{kN}$.

Fig. 10 shows the out-of-plane deformations of the three specimens immediately before the

\section{Numerical Analysis}

\section{Finite Element Model}

A finite element model was developed and analysed with Abaqus code (Dassault Systèmes Simulia the nodes are coincident in the stiffener flange section. 
The stiffened specimen is modelled with four-node shell elements S4R having six degrees of

freedom at each node and three integration points through thickness for each layer. Pre-test analysis is performed by using element size of $0.5 \mathrm{~mm}, 1.0 \mathrm{~mm}, 2.5 \mathrm{~mm}$ and $5 \mathrm{~mm}$, the results are very similar to each other in terms of buckling load and delamination initiation behavior. The element size for VCCT analysis is usually considerably coarser than the element size used in analysis based on cohesive elements. In the VCCT analysis of the authors (Dávila and Bisagni 2017), it was stated that a typical element size of $2.2 \mathrm{~mm}$ was used. In the current analysis, the finite element mesh size of $1.0 \mathrm{~mm}$ is chosen to simulate the behaviour of the specimens without much influence on the accuracy and with economic computational time. The model presents 70200 elements and 58322 nodes. Surface-tosurface contact pairs are defined to allow the debond capability between the skin and stiffener flanges. Additional sensitivity analysis is carried out on imperfection amplitudes, and almost no noticeable discrepancy on the calculations is discovered in the range of less than the quarter thickness of the skin. For the FE models with larger imperfection amplitudes than the quarter thickness of the skin, they show a slightly smaller buckling load and reduced stiffness. An initial geometric imperfection equal to the first eigenmode (similar to the tested buckling shape deformation with one single half wave) and a maximum amplitude of $5 \%$ of skin thickness is introduced in the model. The finite element model is illustrated in Fig. 12.

It is also worthy to mention that five rows of elements on both tips of the stiffener flange along the longitudinal direction are modelled with gradually decreased thickness to reproduce the tested specimens. Indeed, the most external ply of the stiffener was the first one to be stacked on the L-shape aluminium mould during manufacturing. Due to the radius in the core area connecting stiffener web and stiffener flange, the subsequent ply presented a gradually reduced width in the stiffener flange. However, during the co-curing process, mechanical pressure caused by vacuum bagging pushed the external layers to the base skin so that the varied thickness at the stiffener flange tip was created.

Taking into account the skin-stiffener separation as one of the main failure mechanisms, the VCCT is used to predict the delamination propagation process associated with RAMP option. The VCCT approach is based on the assumption that the crack extends by a small amount without significantly changing the state at the crack tip, that is, the crack grows in a self-similar manner. In the current 
compressive loading scenario, it is possible that three different delamination modes (mode I, mode II and III) are interacted. The original B-K (Benzeggagh-Kenane) mixed-mode failure criterion (Benzeggagh et al. 1996), which are established for mixed-modes I and II, has been extended by taking into account mode III. However, there is no reliable mixed-mode I-III and II-III test results due to the lack of standard nixed-mode method available incorporating mode III loading. For these reasons, $\mathrm{Li}$ ( $\mathrm{Li}$ 2002) proposed that the interlaminar fracture toughness values of $\mathrm{G}_{\mathrm{IIc}}$ is equal to $\mathrm{G}_{\mathrm{IIIc}}$. Following those work, Camanho et al. (Camanho et al. 2003; Camanho et al. 2007) propose a threedimensional failure criterion that defines the crack propagation , that is:

$$
G_{I}+G_{I I}+G_{I I I} \geq G_{I C}+\left(G_{I I C}-G_{I C}\right)\left(\left(G_{I I}+G_{I I I}\right) /\left(G_{I}+G_{I I}+G_{I I I}\right)\right)^{\mathrm{n}}
$$

Crack propagation is assumed to occur when it meets the above requirement. The curve fitting parameter $\eta$ equal to 1.6 is obtained from the mixed-mode test results (Camanho et al. 2003) under different mode ratios.

The Teflon insert simulates a manufacturing defect and acts as the initial crack front in the modelling. The Teflon tape has a nominal thickness of $0.0254 \mathrm{~mm}$. Compared to the ply thickness, it is almost negligible and thus an artificial opening in the Teflon insert area between the skin and stiffener flange is introduced.

Boundary conditions are considered in order to represent the actual loading conditions during the compressive tests, applying out-of-plane constraints to the corresponding potting areas. The analysis is carried out by imposing a compression displacement to the loading ending of the shell.

\section{Finite Element Results}

Implicit dynamic analysis is performed to calculate the quasi-static response of the tested specimens. Fig. 13a illustrates the load-shortening curves. In the initial loading phase, the model exhibits a linear pre-buckling response. As the load increases, the skin starts to buckle at the eigenvalue buckling load of $5.42 \mathrm{kN}$ in a single half wave on both skin sides. The decreasing stiffness indicates instability of the skin in the initial post-buckling range. The load redistributes with the increasing loads so that the skin deflects with a larger magnitude and the stiffener carries an increasing portion of structural load. The post-buckling deformations obtained by finite element analysis are reported in Fig. 13b. At an applied 
load level of approximately $11.6 \mathrm{kN}$ (point A), no buckling deformations are observed at the beginning on the stiffener. The out-of-plane deformations of the skin are characterized by a single wave deformation in both skin sides at post-buckling stage.

Point B shows the observed buckling of the stiffener web at load $14.9 \mathrm{kN}$. The stiffener web buckled towards the skin side with the most positive out-of-plane deformation magnitude. With the increasing applied load, the magnitude of the deflections increases. At a load level of $33 \mathrm{kN}$ as shown in point $\mathrm{C}$, the buckling wave expands to a larger area and the deflection magnitude is around $12 \mathrm{~mm}$. The buckling direction of the stiffener web lead to the internal stress redistribution that promotes the debonding of skin-stiffener in the central Teflon insert area. Point D indicates the delamination propagation. The analysis stops at load equal to $38.2 \mathrm{kN}$ due to convergence difficulties.

The finite element model debonding propagation is shown in Fig. 14. A general view is reported in Fig. 14a. The initial separation between skin and stiffener is shown in Fig. 14b, starting from the positive y-axis direction. Fig. 14c and Fig. 14d illustrate the debonding process that develops in a diagonal direction. As the load increases, the delamination propagates to the negative y-axis direction as well. The analysis results further enhance the assumption that VCCT method predicts the crack propagation in a self-similar way as inspected from Fig. 14b to Fig. 14c.

\section{Comparison between Experimental and Numerical Results}

The load-shortening curves from numerical analysis and experimental measurement of specimen SP2 are given in Fig. 15. The finite element analysis exhibit a slightly higher stiffness than the tested ones. With the increment of loads, the shortening from tests were observed to be larger than the one from FE analysis results. Indeed, boundary conditions can play a role in affecting the structural behaviour. The material nonlinearity, due to the damage propagation, and structural nonlinearity, due to buckling, which are not considered in FE analysis, can also influence the results. The load level at skin-stiffener separation initiation is slightly overestimated by numerical analysis $(36.4 \mathrm{kN})$ with $3.6 \%$ difference compared to measurements from the average experimental result $(35.1 \mathrm{kN})$. The skin-stiffener separation initiates at the location close to stiffener web for both numerical and experimental results. 
both testing and numerical analysis (as shown in Fig. 6d and Fig. 14c), and then damage propagated to the other side of the interface at a higher load.

During the VCCT analysis, RAMP option facilitates the gradual released tension in such a way that the debonding force is brought to zero no later than the moment when the next node along the crack path starts to open. It is possible to model smooth crack propagation and thus improves the convergence of the equilibrium solution. This option is able to correctly identify the delamination onset and better represent the experimental results, however, the solver has difficulties in finding a solution after the fracture toughness is reached, especially for in-plane loading condition. In the current analysis, due to the convergence difficulties during the analysis, the calculation stops at the load level of $38.2 \mathrm{kN}$ after the skin detaches from the stiffener flange in four rows of element.

The post-buckling deformation shapes before the collapse are compared in Fig. 16. Fig. 16a represents the front view of the post-buckling configurations while Fig. 16b shows the side view. It is noted that the calculated post-buckling deformation mode gives a good matching with the experimental observations.

\section{Conclusions}

Single stiffener composite specimens under compression were investigated. Three specimens were manufactured with co-cured T-shape stiffener. A Teflon insert was introduced to simulate the manufacturing defect at the specimen mid-length across the interface between stiffener flange and the skin. A finite element model was developed in Abaqus using VCCT.

The experiments show that skin-stiffener separation and stiffener crippling were the two dominant failure mechanisms. The analysis methodology was able to accurately capture the structural response and the skin-stiffener separation, and provided realistic predictions of the loads and locations of the delamination initiation. The initial delamination load level was $3.6 \%$ overestimated by the numerical results. The experimental average collapse load of three specimens was $36.0 \mathrm{kN}$ while the predicted maximal load was $38.2 \mathrm{kN}$.

The close correlation between the test results and the finite element analysis contributes to a better understanding of the post-buckling response and delamination evolution since the analysis 
methodology is capable to provide realistic predictions. The validated model of the single stiffener

composite specimens can be used to investigate the deformation response and the critical damage

351

352

353

354

355

356

357

358

359

360

361

362

363

364

365

366

367

368

369

370

371

372

373

374

375

376

377 mechanisms of a multiple stiffener panel. Besides, it allows further exploitation in strength reserve and more efficient preliminary design guidance of post-buckled composite aerospace structures.

\section{References}

Abramovich, H., Weller, T., and Bisagni, C. (2008). "Buckling behavior of composite laminated stiffened panels under combined shear-axial compression.” J. Aircraft., 45(2), 402-413.

Ambur, D.R., Jaunky, N., and Hilburger, M.W. (2004). "Progressive failure analyses of compression-loaded composite curved panels with and without cutouts.” Compos. Struct., 65(2), 143-155.

Armanios, E.A. (1991). "Delamination analysis for laminated composites. I: Fundamentals." J. Aerosp. Eng., 10.1061-(ASCE) 0893-1321(1991)4:2(194), 194-215.

Benzeggagh, M.L., Kenane, M. (1996). "Measurements of mixed-mode delamination fracture toughness of unidirectional glass / epoxy composites with mixed-mode bending apparatus." Compos. Sci. Technol., 56(4), 439-449.

Bisagni, C., and Cordisco, P. (2003). "An experimental investigation into the buckling and post-buckling of CFRP shells under combined axial and torsion loading." Compos. Struct., 60(4), 391-402.

Bisagni, C., and Cordisco, P. (2006). "Post-buckling and collapse experiments of stiffened composite cylinderical shells subjected to axial loading and torque." Compos. Struct., 73(2), 138-149.

Bisagni, C. (2006). "Progressive delamination analysis of stiffened composite panels in post-buckling." Proceedings of the 47th AIAA/ASME/ASCE/ASC Structures, Structural Dynamics, and Materials Conference, Newport, Rhode Island, USA. May 1-4, 2006, AIAA 2006-2178, pp. 1-12.

Bisagni, C., Vescovini, R., and Davila, C. G. (2011). "Single-stiffener compression specimen for the assessment of damage tolerance of post-buckled structures.” J. Aircraft., 48(2), 495-502.

Bisagni, C., and Davila, C.G. (2014). "Experimental investigation of the postbuckling response and collapse of a single-stiffener specimen.” Compos. Struct., 108(1), 493-503.

Camanho, P.P., Dávila, C.G., de Moura, M.F. (2003). "Numerical simulation of mixed-mode progressive delamination in composite materials.” J. Compos. Mater., 37(16), 1415-1424.

Camanho, P.P., Maimí, P. and Dávila, C.G. (2007). "Prediction of size effects in notched laminates using continuum damage mechanics.” Compos. Sci. Technol., 67(13), 2715-2727. 
Dávila, C.G., and Bisagni, C. (2017). "Fatigue life and damage tolerance of postbuckled composite stiffened structures with initial delamination." Compos. Struct., 161, 73-84.

Dassault Systèmes Simulia Corp. (2015). Abaqus Analysis User's Manual Guide, version 6.16. Providence, RI.

Elaldi, F., and Colak, L. (2009). "Buckling and post-buckling behavior of compression loaded composite panels with hat stiffeners." J. Reinf. Plast Comp., 28(20), 2501-2509.

Falzon, B.G. (2001). "The behavior of damage tolerant hat-stiffened compoiste panels loaded in uniaxial compression.” Compos., Part A: Appl. Sci. Manuf., 32(9), 1255-1262.

Falzon, B.G., and Aliabadi, M.H. (2008). Buckling and post-buckling structures: Experimental, Analytical and Numerical Studies. Imperial College Press, London, U. K.

Featherston, C.A., and Watson, A. (2006). "Buckling of optimised curved composite panels under shear and inplane bending." Compos. Sci. Technol., 66(15), 2878-2894.

Krueger, R., and Minguet P.J. (2005). "Skin-stiffener debond prediction based on computational fracture analysis. "NASA/CR-2005-213915, NASA Langley Research Center, VA, USA.

Lauterbach, S., Orifici, A.C., Wagner, W., Balzani, C., Abramovich, H., and Thomson. R. (2010). "Damage sensitivity of axially loaded stiffener-stiffened curved CFRP panels." Compos. Sci. Technol., 70(2), 240-248.

Li, J. (2002). "Three-dimensional effect in the prediction of flange delamination in composite skin-stringer pulloff specimens." J Compos Tech Res., 24(3),182-189.

Orifici, A.C., de Zarate Alberdi, I.O., Thomson, R.S., and Bayandor, J. (2008). "Compression and post-buckling damage growth and collapse analysis of flat composite stiffened panels." Compos. Sci. Technol., 68(15-16), 3150-3160.

Orifici, A.C., Thomson, R.S., Degenhardt, R., Bisagni, C., and Bayandor, J. (2009). "A finite element methodology for analysing degradation and collapse in postbuckling composite aerospace structures." $J$. Compos. Mater., 43(26), 3239-3263.

Vescovini, R., Dávila, C.G., and Bisagni, C. (2013). "Failure analysis of composite multi-stiffener panels using simplified models." Compos. Part B: Eng., 45(1), 939-951.

VIC-3D 7. Software Package, Version. 2010.1.0, (2010). Correlated Solutions Inc, Columbia, S. C.

Zimmermann, R., Klein, H., and Kling, A. (2006). "Buckling and postbuckling of stiffener stiffened fiber composite curved panels - Tests and Computations.” Compos. Struct., 73(2), 150-161. 
- $\quad$ Fig. 1. T-stiffened specimen

- $\quad$ Fig. 2. Stacking sequences of skin and stiffener

- Fig. 3. Specimen SP1 at $27.9 \mathrm{kN}$ : a) post-buckling shape; b) out-of-plane deformation

- Fig. 4. Delamination initiation of specimen SP1 at $35.1 \mathrm{kN}$ : a) out-of-plane deformation;

b) strain distribution; c) C-scan

- Fig. 5. Specimen SP2 at $27.9 \mathrm{kN}$ : a) post-buckling shape; b) out-of-plane deformation

- Fig. 6. Delamination initiation and propagation in specimen SP2: a) out-of-plane deformation at $35.12 \mathrm{kN}$; b) delamination onset at $35.12 \mathrm{kN}$; c) out-of-plane deformation at $37.58 \mathrm{kN}$;

d) delamination propagation at $37.58 \mathrm{kN}$

- Fig. 7. Delamination propagation in specimen SP3: a) out-of-plane deformation at $37.21 \mathrm{kN}$;

b) delamination at $37.21 \mathrm{kN}$; c) out-of-plane deformation at $37.08 \mathrm{kN}$; d) delamination propagation at $37.08 \mathrm{kN}$

- Fig. 8. Load-shortening curves comparison: a) tested specimens; b) four testing runs of specimen SP2

- Fig. 9. Strain contour of specimen SP3 at $37.21 \mathrm{kN}$

- Fig. 10. Out-of-plane deformations immediately before collapse: a) specimen SP1 at $34.9 \mathrm{kN}$;

b) specimen $\mathrm{SP} 2$ at $36.8 \mathrm{kN}$; c) specimen $\mathrm{SP} 3$ at $36.2 \mathrm{kN}$

- $\quad$ Fig. 11. Failure modes: a) specimen SP2; b) specimen SP3

- $\quad$ Fig. 12. Finite element model

- Fig. 13. Analysis of the tested specimens: a) load-shortening curve; b) out-of-plane deformations

- Fig. 14. Opening of Teflon-induced defect in post-buckling field: a) finite element model;

b) debonding initiation at $33 \mathrm{kN}$; c) debonding propagation at $36.9 \mathrm{kN}$; d) debonding propagation at $38.5 \mathrm{kN}$

- Fig. 15. Comparison between experimental and numerical load-shortening curves

- $\quad$ Fig. 16. Comparison between experimental and numerical post-buckling deformed shapes at $35.5 \mathrm{kN}$ :

a) front view; b) side view 
Table 1. Mechanical properties of unidirectional IM7/8552

\begin{tabular}{lcccc}
\hline Material & $\mathrm{E}_{11}[\mathrm{GPa}]$ & $\mathrm{E}_{22}[\mathrm{GPa}]$ & $\mathrm{G}_{12}[\mathrm{GPa}]$ & $\mathrm{v}_{12}$ \\
\hline $\mathrm{IM} 7 / 8552$ & 150 & 9.08 & 5.29 & 0.32 \\
\hline
\end{tabular}


Table 2. Interlaminar properties of IM7/8552

\begin{tabular}{lccc}
\hline Material & $\mathrm{G}_{\mathrm{IC}}[\mathrm{N} / \mathrm{mm}]$ & $\mathrm{G}_{\mathrm{IIC}}[\mathrm{N} / \mathrm{mm}]$ & $\mathrm{B}-\mathrm{K}$ \\
\hline $\mathrm{IM} 7 / 8552$ & 0.277 & 0.778 & 1.6 \\
\hline
\end{tabular}


Table 3. Maximum loads of the tested specimens

\begin{tabular}{lc}
\hline Specimen ID & Maximum load $[\mathrm{kN}]$ \\
\hline SP1 & 35.10 \\
SP2 & 37.58 \\
SP3 & 37.21 \\
\hline
\end{tabular}




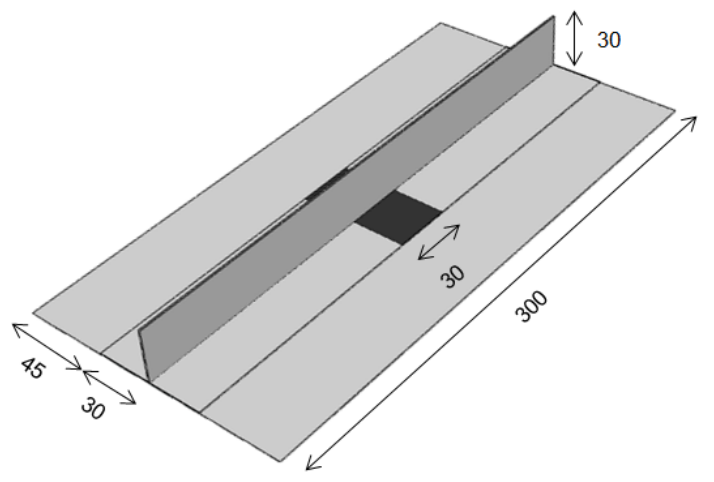

Fig. 1. T-stiffened specimen 


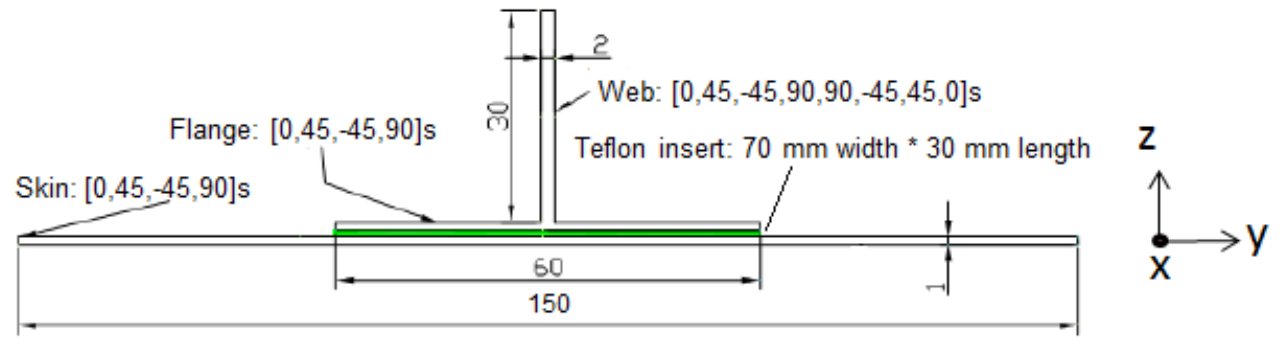

Fig. 2. Stacking sequences of skin and stiffener 
a)

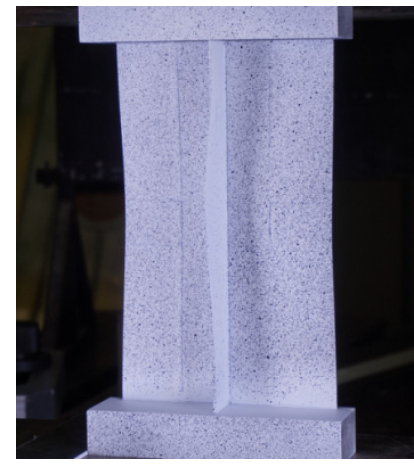

b)

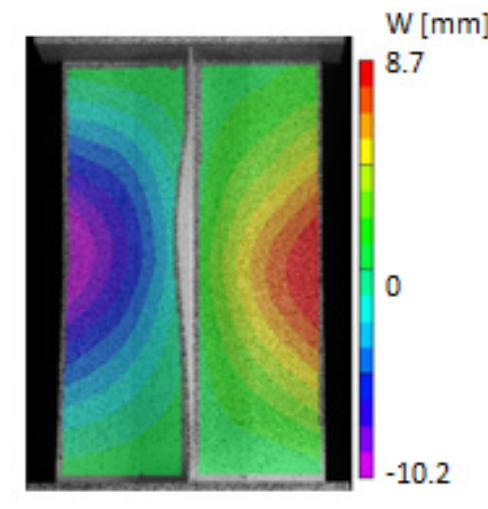

Fig. 3. Specimen SP1 at $27.9 \mathrm{kN}$ : a) post-buckling shape; b) out-of-plane deformation 

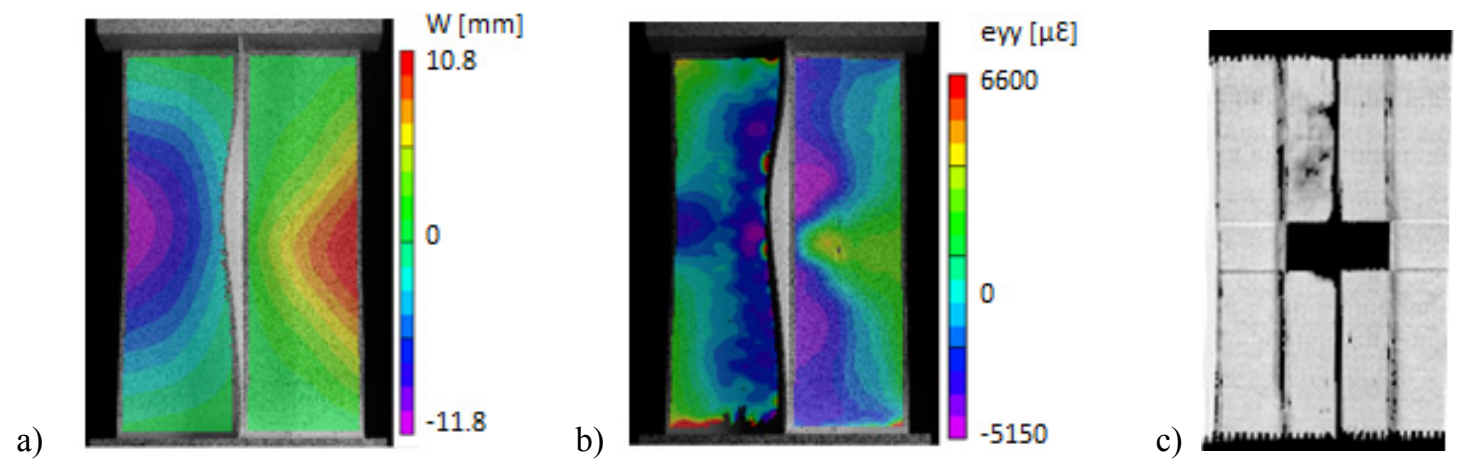

Fig. 4. Delamination initiation of specimen SP1 at $35.1 \mathrm{kN}$ : a) out-of-plane deformation;

b) strain distribution; c) C-scan 

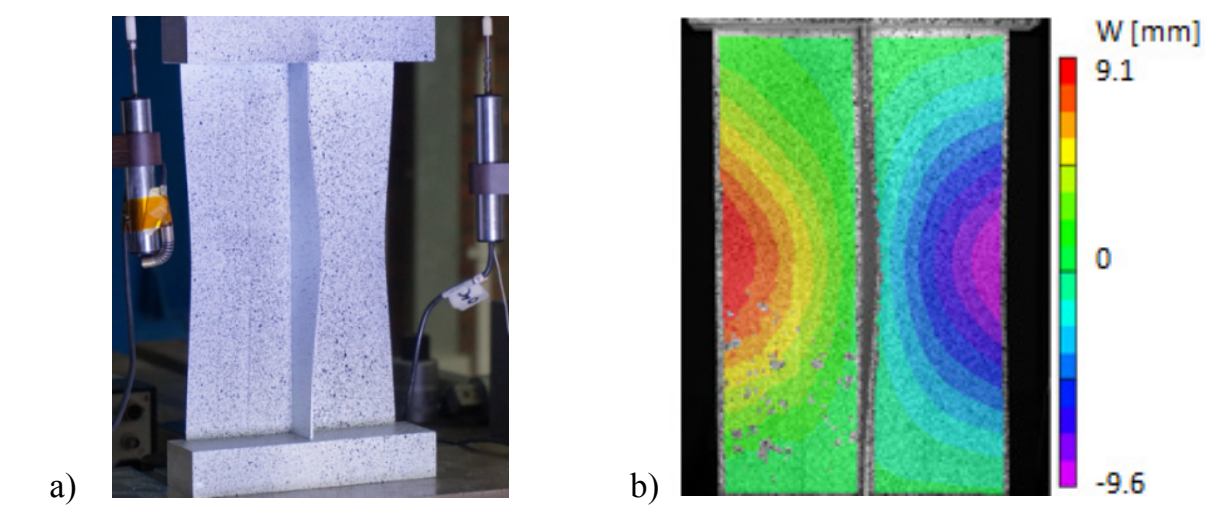

Fig. 5. Specimen SP2 at $27.9 \mathrm{kN}$ : a) post-buckling shape; b) out-of-plane deformation 


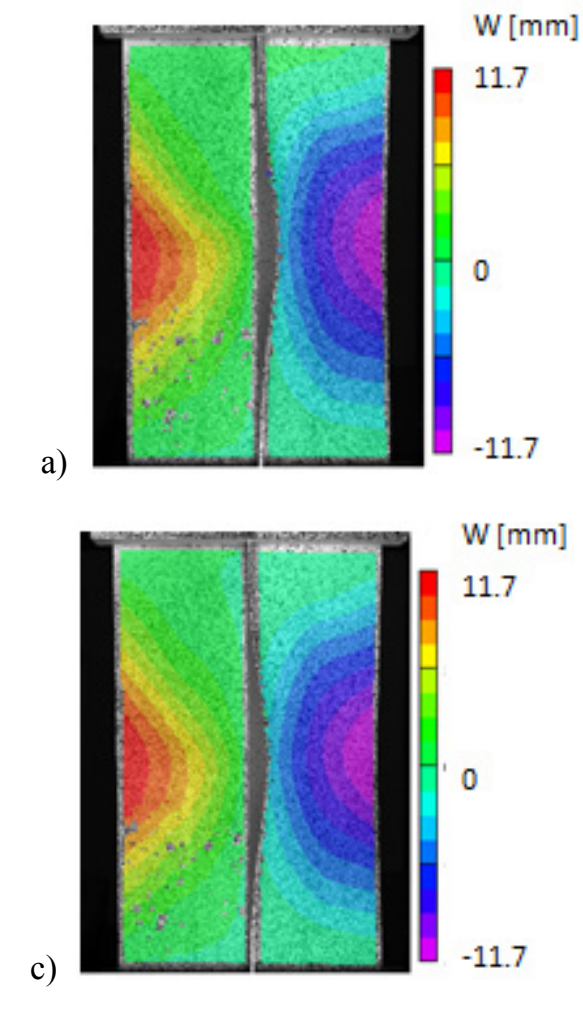

b)

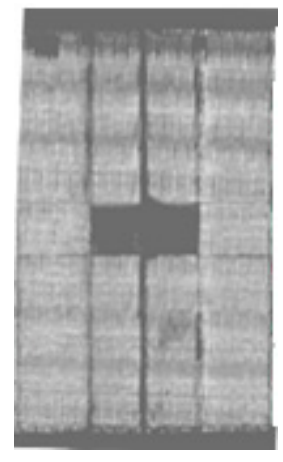

d)

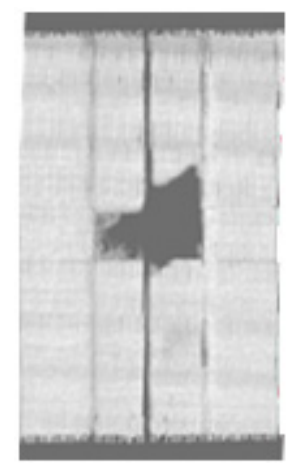

Fig. 6. Delamination initiation and propagation in specimen SP2:

a) out-of-plane deformation at $35.12 \mathrm{kN}$; b) delamination onset at $35.12 \mathrm{kN}$;

c) out-of-plane deformation at $37.58 \mathrm{kN}$; d) delamination propagation at $37.58 \mathrm{kN}$ 
a)

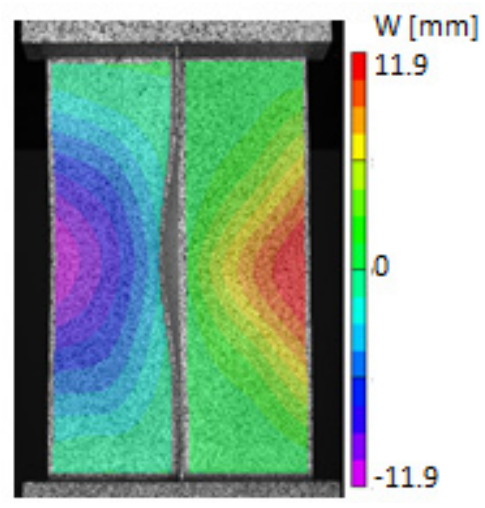

c)

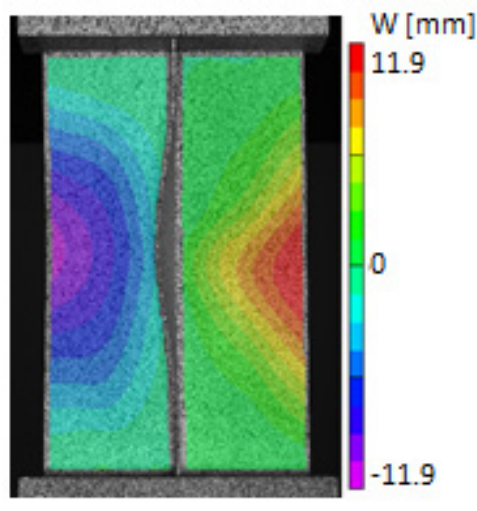

b)

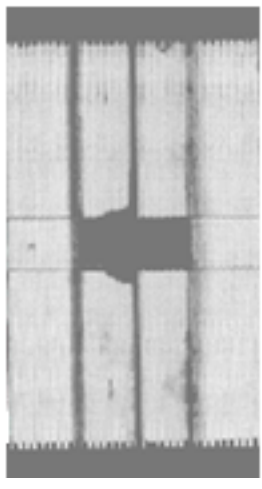

d)

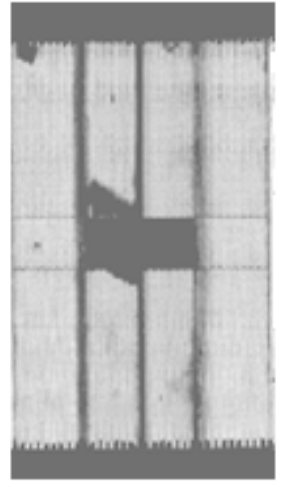

Fig. 7. Delamination propagation in specimen SP3:

a) out-of-plane deformation at $37.21 \mathrm{kN}$; b) delamination at $37.21 \mathrm{kN}$;

c) out-of-plane deformation at $37.08 \mathrm{kN}$; d) delamination propagation at $37.08 \mathrm{kN}$ 


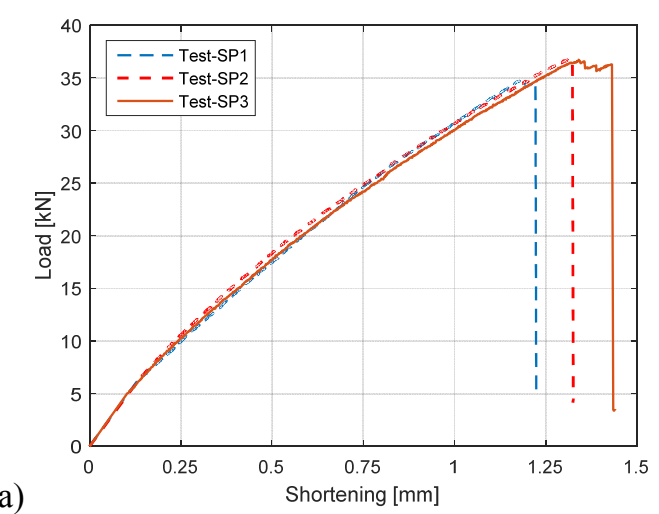

a)

Fig. 8. Load-shortening curves comparison: a) tested specimens; b) four testing runs of specimen SP2

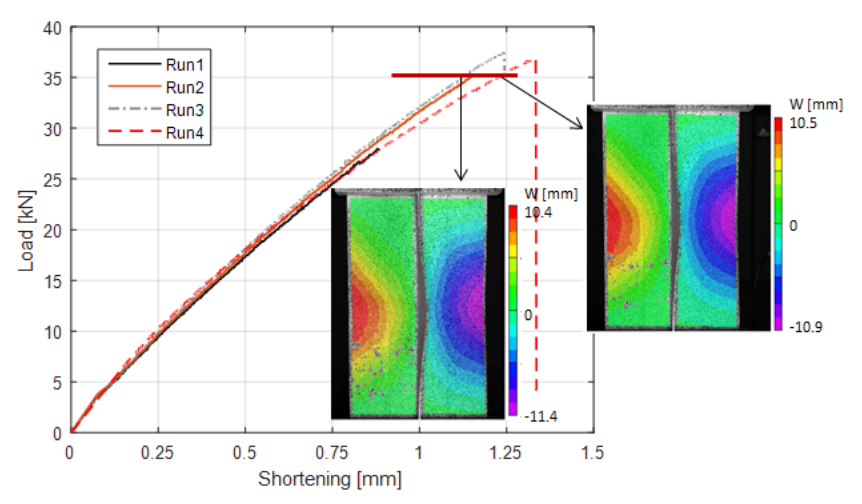

b) 


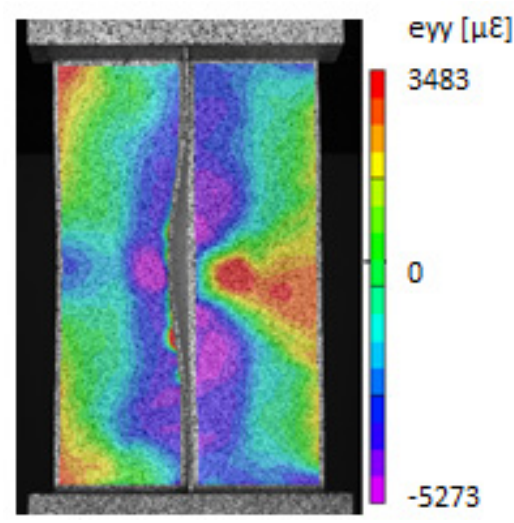

Fig. 9. Strain contour of specimen $\mathrm{SP} 3$ at $37.21 \mathrm{kN}$ 
a)

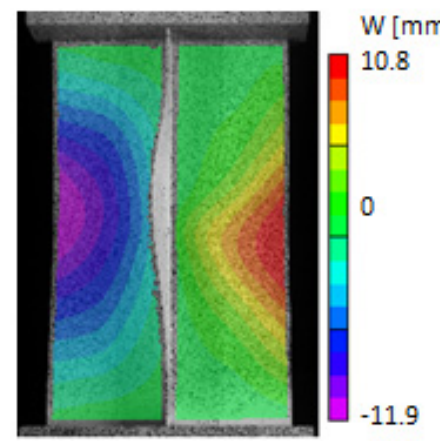

b)

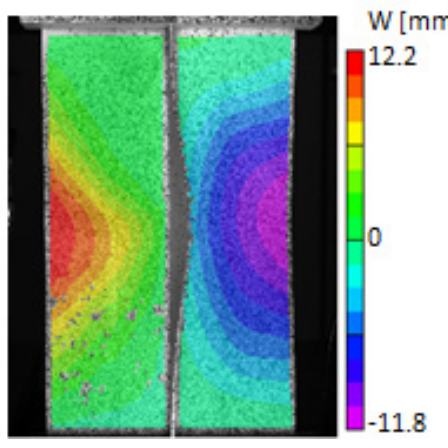

c)

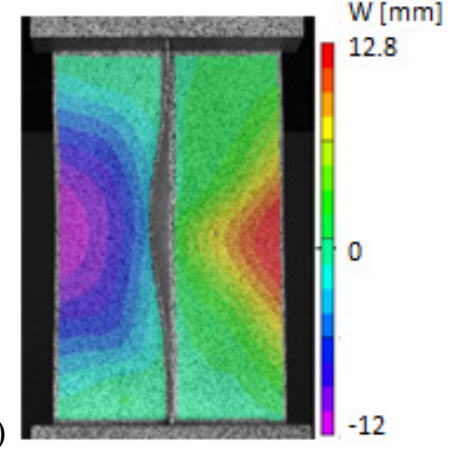

Fig. 10. Out-of-plane deformations immediately before collapse: a) specimen SP1 at $34.9 \mathrm{kN}$;

b) specimen SP2 at $36.8 \mathrm{kN}$; c) specimen SP3 at $36.2 \mathrm{kN}$ 
a)

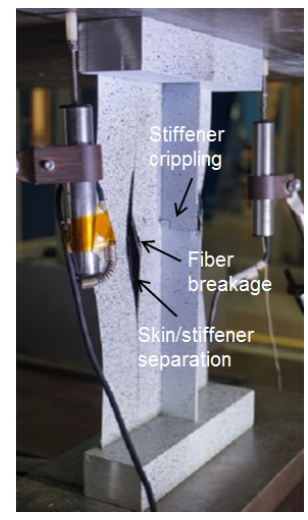

b)

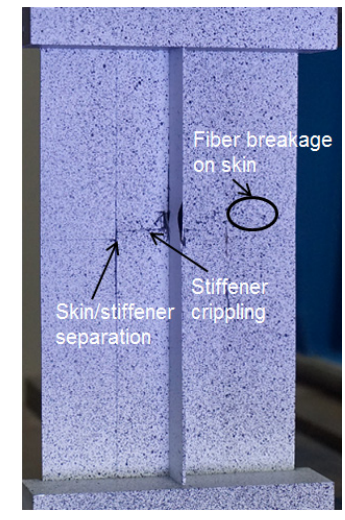

Fig. 11. Failure modes: a) specimen SP2; b) specimen SP3 


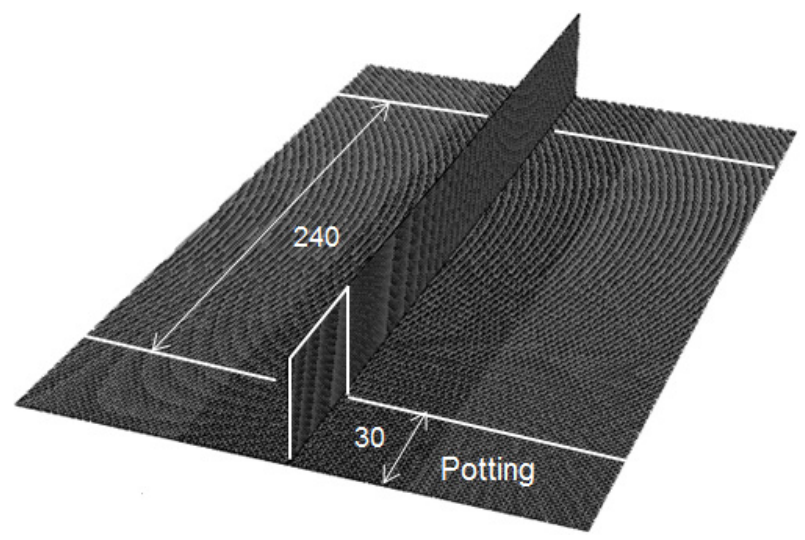

Fig. 12. Finite element model 


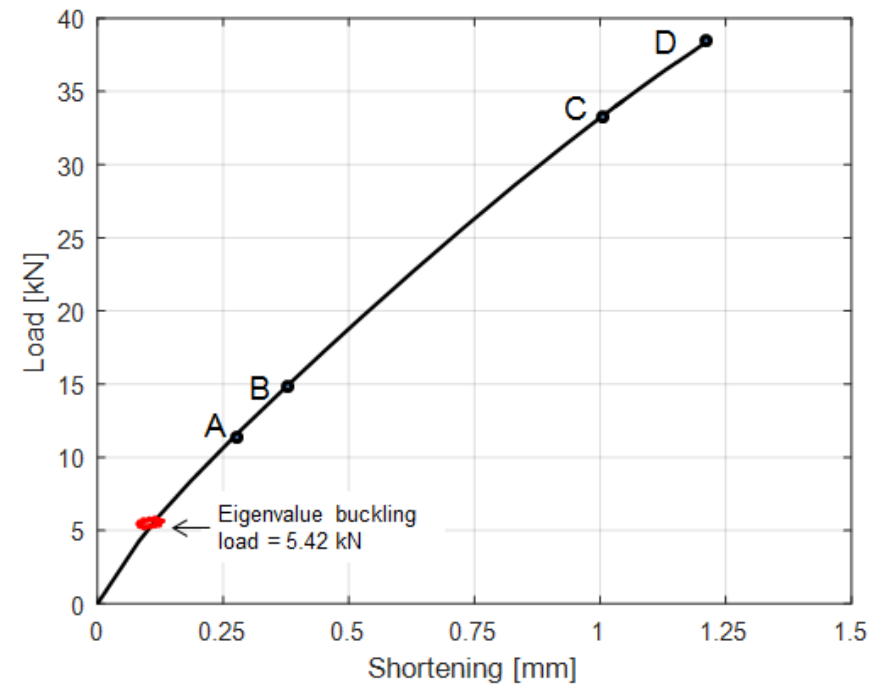

a)
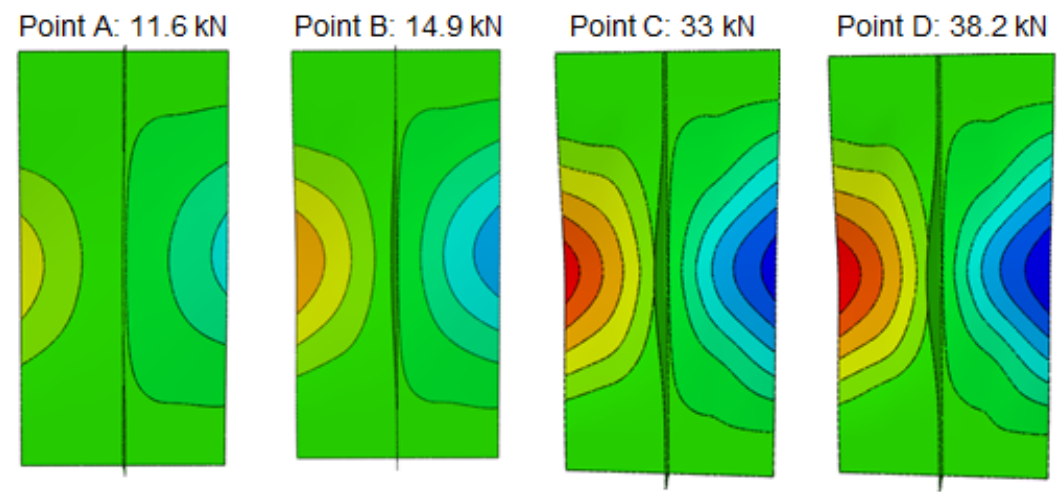

U, บ3

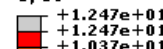

$+8.267 \mathrm{e}+0$
+

$+4.063 \mathrm{e}+00$
$+1.962 \mathrm{e}+00$

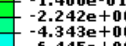

b)

Fig. 13. Analysis of the tested specimens: a) load-shortening curve; b) out-of-plane deformations 
a)

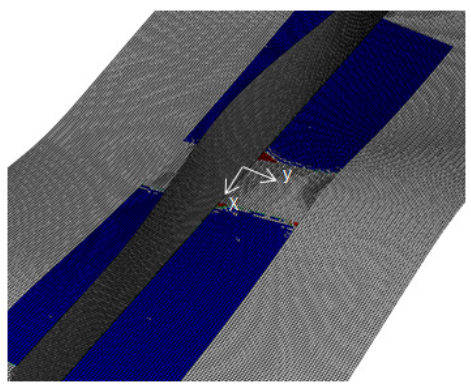

c)

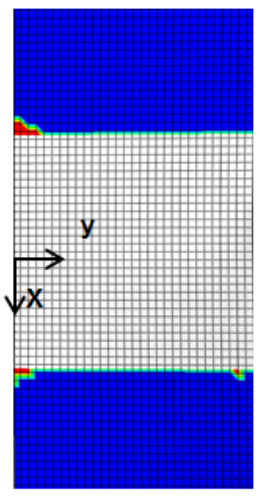

b)

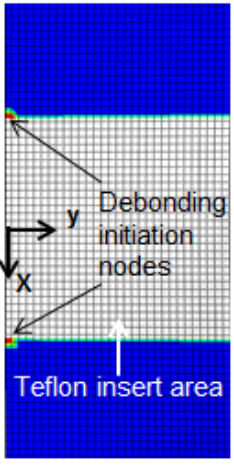

d)

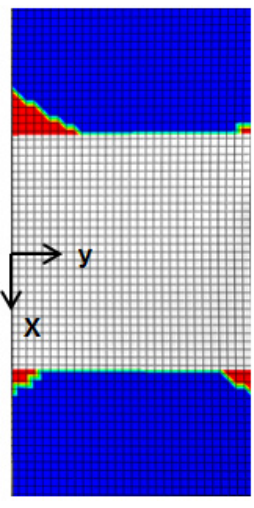

Fig. 14. Opening of Teflon-induced damage in post-buckling field: a) finite element model;

b) debonding initiation at $33 \mathrm{kN}$; c) debonding propagation at $36.9 \mathrm{kN}$;

d) debonding propagation at $38.5 \mathrm{kN}$ 


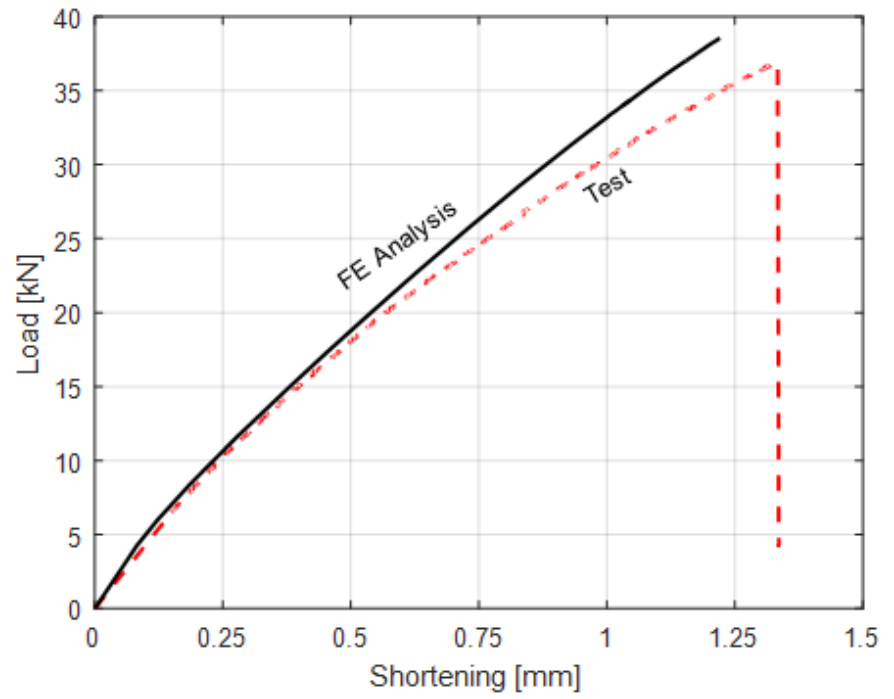

Fig. 15. Comparison between experimental and numerical load-shortening curves 
a)

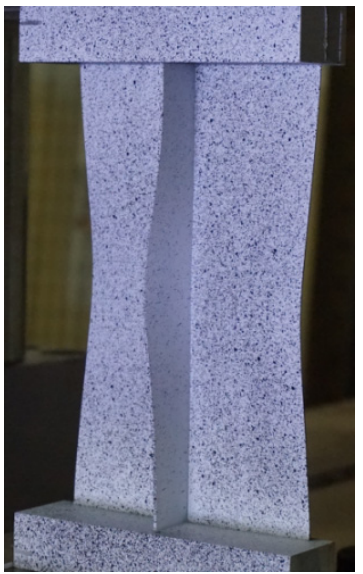

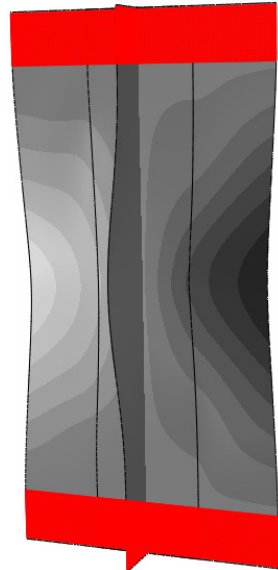

b)

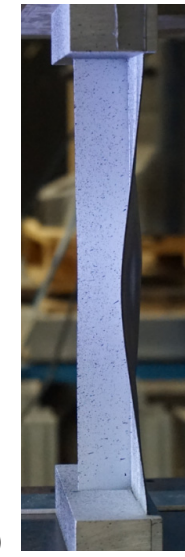

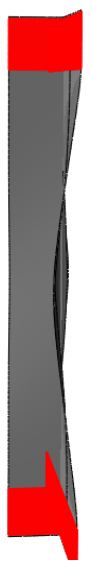

Fig. 16. Comparison between experimental and numerical post-buckling deformed shapes at $35.5 \mathrm{kN}$ :

a) front view; b) side view 